\title{
Does smoking in pregnancy modify the impact of antenatal steroids on neonatal respiratory distress syndrome? Results of the Epipage study
}

\author{
A Burguet, M Kaminski, P Truffert, A Menget, L Marpeau, M Voyer, J C Roze, B Escande, \\ G Cambonie, J M Hascoet, H Grandjean, G Breart, B Larroque, on behalf of the Epipage Study \\ Group
}

See end of article for authors' affiliations

Correspondence to:

Dr Burguet, Réanimation Infantile Polyvalente et

Prématurés, Hôpital SaintJacques, Centre

Hospitalier Universitaire, 25030 Besançon cedex,

France; a.burguet@

chu-poitiers.fr

Accepted 14 July 2004

\begin{abstract}
Objectives: To assess the relation between cigarefte smoking during pregnancy and neonatal respiratory distress syndrome (RDS) in very preterm birth, and to analyse the differential effect of antenatal steroids on RDS among smokers and non-smokers.

Design: A population based cohort study (the French Epipage study).

Setting: Regionally defined births in France.

Methods: A total of 858 very preterm liveborn singletons (27-32 completed weeks of gestation) of the French Epipage study were included in this analysis. The odds ratio for RDS in relation to smoking in pregnancy was estimated using a logistic regression to control for gestational age. The odds ratio for RDS in relation to antenatal steroids was estimated taking into account an interaction between antenatal steroids and cigarette smoking, using multiple logistic regression to control for gestational age, birthweight ratio, main causes of preterm birth, mode of delivery, and sex.

Results: The odds ratio for RDS in relation to smoking in pregnancy adjusted for gestational age (aOR) was 0.59 (95\% confidence interval (Cl) 0.44 to 0.79 ). The aOR for RDS in relation to antenatal steroids was $0.31(95 \% \mathrm{Cl} 0.19$ to 0.49 ) in babies born to non-smokers and 0.63 (95\% $\mathrm{Cl} 0.38$ to 1.05 ) in those born to smokers; the difference was significant $(p=0.04)$.

Conclusions: Cigarette smoking during pregnancy is associated with a decrease in the risk of RDS in very preterm babies. Although antenatal steroids reduce the risk of RDS in babies born to both smokers and non-smokers, the reduction is smaller in those born to smokers.
\end{abstract}

shown to be more likely to be smokers than mothers delivering at term. ${ }^{346}$

The purpose of this study was firstly to estimate the relation of cigarette smoking during pregnancy to RDS in very preterm neonates, taking pregnancy history and antenatal steroid treatment into account. We secondly tested the hypothesis that the benefit of antenatal steroid treatment on RDS is different in smokers and non-smokers. The alternative hypothesis was that antenatal steroid treatment leads to the same effect, independently of maternal smoking.

\section{METHODS AND DATA COLLECTION}

We analysed the relation between maternal smoking and neonatal RDS in a geographically defined population of very preterm singletons in France. The methodology of the French Epipage cohort study has been described previously. ${ }^{29}{ }^{30}$ The main objective of this survey was to assess mortality and neurological morbidity, health, and development of these children at the age of 5 . The survey included all very preterm babies (22-32 completed weeks of gestation) born in 1997, in all the maternity wards of nine French regions. Data were collected using the same questionnaire in the nine regions. Medical data, including obstetric history, pregnancy, delivery, and neonatal examination, were extracted from medical records. The women were interviewed a few days after birth, during their stay in the maternity unit, to collect information on social characteristics and smoking habits.

Abbreviations: PPROM, preterm premature rupture of membranes; RDS, respiratory distress syndrome tries, $20-30 \%$ of mothers smoked in the third trimester of pregnancy, ${ }^{28}$ and mothers of very preterm neonates have been 


\begin{tabular}{|c|c|c|c|c|}
\hline & \multirow[b]{2}{*}{$\mathrm{N}$} & \multicolumn{2}{|l|}{ RDS } & \multirow[b]{2}{*}{$\mathrm{p}$ Value } \\
\hline & & $n$ & $\%$ & \\
\hline \multicolumn{5}{|l|}{ Gestational age (weeks) } \\
\hline $27-28$ & 164 & 113 & 68.9 & \multirow{4}{*}{0.001} \\
\hline $29-30$ & 213 & 98 & 46.0 & \\
\hline $31-32$ & 481 & 144 & 29.9 & \\
\hline Total & 858 & & & \\
\hline \multicolumn{5}{|l|}{ IUGR } \\
\hline Yes & 211 & 89 & 42.2 & \multirow[t]{3}{*}{0.74} \\
\hline No & 643 & 263 & 40.9 & \\
\hline Total & 854 & & & \\
\hline \multicolumn{5}{|l|}{ Main cause of preterm birth* } \\
\hline Hypertension & 235 & 126 & 53.6 & \multirow[t]{6}{*}{0.001} \\
\hline Uterine bleeding & 230 & 95 & 41.3 & \\
\hline PPROM & 172 & 38 & 22.1 & \\
\hline Preterm spontaneous labour & 152 & 71 & 46.7 & \\
\hline Other & 69 & 25 & 36.2 & \\
\hline Total & 858 & & & \\
\hline \multicolumn{5}{|l|}{ Sex } \\
\hline Boys & 458 & 189 & 41.3 & \multirow[t]{3}{*}{0.92} \\
\hline Girls & 399 & 166 & 41.6 & \\
\hline Total & 857 & & & \\
\hline \multicolumn{5}{|l|}{ Mode of delivery } \\
\hline Vaginal & 309 & 102 & 33.0 & \multirow{3}{*}{0.001} \\
\hline Caesarean section & 548 & 253 & 46.2 & \\
\hline Total & 857 & & & \\
\hline \multicolumn{5}{|c|}{$\begin{array}{l}\text { *Comparison between five exclusive groups of causes defined in the following order: hypertension, either pre- } \\
\text { existing or due to pregnancy; maternal bleeding (abruptio placenta, placenta previa, and other uterine bleeding) } \\
\text { without hypertension; preterm premature rupture of membranes (PPROM) without hypertension or bleeding; } \\
\text { preterm spontaneous labour without hypertension, bleeding, or PPROM; all other causes, excluding hypertension, } \\
\text { bleeding, PPROM of preterm spontaneous bleeding. } \\
\text { IUGR, Intrauterine growth retardation defined as a birth weight ratio }<0.74 .^{31}\end{array}$} \\
\hline
\end{tabular}

We studied 956 liveborn singletons of 27-32 completed weeks of gestation, born in five of the nine regions of the Epipage study: Alsace, Franche-Comté, Lorraine, MidiPyrénées, and Nord-Pas de Calais. In these areas, information on maternal smoking and social characteristics was available for $90 \%$ (858/956) of the infants. Limiting the cases included in the analysis was necessary because women were not interviewed if (a) their neonate was less than 27 weeks gestation or $(b)$ the delivery took place in the four other regions included in the study. This meant that 858 preterm singletons were included in the analysis.

\section{Study variables}

Gestational age was the best obstetric estimate using menstrual dates and early ultrasonographic assessment. Birthweight ratio was defined as observed birth weight/ theoretical birth weight for gestational age according to ultrasonographic values. ${ }^{31}$ Intrauterine growth restriction (birthweight ratio less than the 25th centile) was observed in our cohort $(<0.74)$. The main causes of preterm delivery were classified into five exclusive groups in the following order: maternal hypertension, defined as a systolic blood pressure higher than $139 \mathrm{~mm} \mathrm{Hg}$ or diastolic blood pressure higher than $89 \mathrm{~mm} \mathrm{Hg}$, either pre-existing or due to pregnancy; maternal bleeding (abruptio placenta, placenta praevia, and other uterine bleeding) without hypertension; preterm premature rupture of membranes (PPROM; rupture of membranes 12 hours or more before onset of labour) without hypertension or bleeding; spontaneous labour without hypertension, bleeding, or PPROM; the fifth group included all other cases. Maternal smoking was defined as consumption of one or more cigarettes a day at the end of pregnancy. RDS (hyaline membrane disease) was defined as clinical symptoms of respiratory distress associated with signs of hyaline membrane disease on chest $x$ ray examination. Information on infants was collected until they were discharged home or until the date of their death in hospital. Women were considered to have received antenatal steroid treatment whether or not they had received a complete course and whether the treatment was with betamethasone or dexamethasone.

\section{Statistical analysis}

The analysis followed five steps. (1) We first ascertained that known risk factors of RDS (gestational age, birth weight, main cause of preterm birth, sex, mode of delivery) and antenatal steroid rates were no different whether or not data on maternal smoking were available. (2) We analysed the distribution of RDS according to the obstetric and neonatal known risk factors of RDS listed above. (3) We compared the rate of antenatal steroid treatment according to the risk factors of RDS listed above and smoking status of the mother. (4) We estimated the odds ratios of RDS according to antenatal steroid treatment among smokers and nonsmokers, and compared them after controlling for the confounders listed above. (5) We checked that these results were similar in various subpopulations: neonates born to mothers with and without hypertension; neonates born with and without caesarean section; neonates with or without intrauterine growth restriction. Death rates were compared according to antenatal steroid treatment and maternal smoking status. Bivariate analysis was performed using Pearson's $\chi^{2}$ test. The distributions of antenatal steroid treatment according to risk factors for RDS in smokers and non-smokers were compared using the $\chi^{2}$ test for homogeneity. The risk of RDS related to smoking was estimated with odds ratios (ORs) and 95\% confidence intervals (CIs). Multivariate analysis used logistic regression, with the presence or absence of RDS as the dependent variable, to investigate the relation of steroids and smoking to RDS and to test for an interaction between these two factors after controlling for the confounders listed above. Analysis was 
Table 2 Respiratory distress syndrome according to smoking during pregnancy and antenatal steroids

\begin{tabular}{|c|c|c|c|c|c|c|}
\hline & \multirow[b]{2}{*}{$\mathbf{N}$} & \multicolumn{2}{|l|}{ RDS } & \multirow[b]{2}{*}{ OR $(95 \% \mathrm{Cl})$} & \multirow[b]{2}{*}{ aOR $(95 \% \mathrm{Cl})$} & \multirow[b]{2}{*}{ p Value } \\
\hline & & $n$ & $\%$ & & & \\
\hline \multicolumn{7}{|l|}{ Smoking } \\
\hline No & 518 & 235 & 45.4 & 1.0 & 1.0 & 0.001 \\
\hline Yes & 340 & 120 & 35.3 & $0.66(0.50$ to 0.87$)$ & $0.59(0.44$ to 0.79$)$ & \\
\hline \multicolumn{7}{|l|}{ Antenatal steroids } \\
\hline No & 253 & 136 & 53.8 & 1.0 & 1.0 & 0.001 \\
\hline Yes & 605 & 219 & 36.2 & $0.49(0.36$ to 0.66$)$ & $0.47(0.35$ to 0.65$)$ & \\
\hline \multicolumn{7}{|l|}{ Steroids and smoking } \\
\hline No smoking, no steroids & 134 & 87 & 64.9 & 1.0 & 1.0 & 0.001 \\
\hline No smoking, steroids & 384 & 148 & 38.5 & $0.34(0.23$ to 0.51$)$ & $0.32(0.21$ to 0.50$)$ & \\
\hline Smoking, no steroids & 119 & 49 & 41.2 & $0.38(0.23$ to 0.63$)$ & $0.34(0.20$ to 0.57$)$ & \\
\hline Smoking and steroids & 221 & 71 & 32.1 & $0.26(0.16$ to 0.40$)$ & $0.22(0.13$ to 0.35$)$ & \\
\hline
\end{tabular}

performed with BMDP statistical software (BMDP Corp, Los Angeles, California, USA).

\section{RESULTS}

There was no difference in gestational age, birth weight, main cause of preterm birth, mode of delivery, sex, and antenatal steroids between the preterm infants for whom maternal smoking status was known $(\mathrm{n}=858)$ and those for whom it was unknown ( $\mathrm{n}=98)$ (results not shown).

The rate of RDS was significantly higher in the group of lower gestational age and caesarean section (table 1), and in neonates born to non-smokers and to mothers who did not receive antenatal steroids (table 2). After adjustment for gestational age, the ORs for the relation of RDS to maternal smoking (aOR $=0.59,95 \%$ CI 0.44 to 0.79$)$ and antenatal steroids (aOR $=0.47,95 \%$ CI 0.35 to 0.65 ) were significant.

Steroids alone, smoking alone, and association of smoking and steroids were significantly related to a lower risk of RDS (table 2). However, the protective effects of steroids on neonatal RDS differed in smokers and non-smokers.
Antenatal steroid treatment was more efficient in nonsmokers (OR $0.34,95 \%$ CI 0.23 to 0.51 ) than smokers (OR $0.68,95 \%$ CI 0.43 to 1.07 ), and the two ORs were significantly different $(\mathrm{p}=0.03)$.

Non-smokers were treated with antenatal steroids significantly more often than smokers $(74 \% v 65 \%, \mathrm{p}=0.01)$. The distributions of antenatal steroid treatment according to gestational age, birthweight ratio, main cause of preterm birth, mode of delivery, and sex did not differ significantly among smokers and non-smokers (table 3).

Finally, this differential effect of antenatal steroid treatment on RDS was observed in smokers and non-smokers after adjustment for gestational age, birthweight ratio, main cause of preterm birth, mode of delivery, and sex. Antenatal steroid treatment was more efficient in non-smokers (aOR $0.31,95 \%$ CI 0.19 to 0.49 ) than smokers (aOR 0.63 (0.38 to $1.05)$; comparison of the two ORs by the $\chi^{2}$ test showed significance $(\mathrm{p}=0.04)$.

Similar trends were found in the following subpopulations: preterm neonates born to mothers with hypertension or

Table 3 Antenatal steroids according to risk factors of respiratory distress syndrome (RDS) among non-smokers and smokers

\begin{tabular}{|c|c|c|c|c|c|}
\hline & \multicolumn{2}{|c|}{ Non-smokers } & \multicolumn{2}{|l|}{ Smokers } & \multirow[b]{2}{*}{ p Value* } \\
\hline & $\mathrm{n} / \mathrm{N}$ & $\%$ & $\bar{n} / \mathrm{N}$ & $\%$ & \\
\hline Antenatal steroids & \multicolumn{2}{|l|}{$384 / 518$} & \multicolumn{2}{|l|}{$221 / 340$} & \\
\hline \multicolumn{6}{|l|}{ Gestational age (weeks) } \\
\hline $27-28$ & $62 / 92$ & 67.4 & $46 / 72$ & 63.9 & \multirow[t]{3}{*}{0.63} \\
\hline $29-30$ & $100 / 128$ & 78.1 & $57 / 85$ & 67.1 & \\
\hline $31-32$ & $222 / 298$ & 74.5 & $118 / 183$ & 64.5 & \\
\hline \multicolumn{6}{|l|}{ IUGR† } \\
\hline Yes & $112 / 137$ & 81.8 & $52 / 74$ & 70.3 & \multirow[t]{2}{*}{0.47} \\
\hline No & $271 / 378$ & 71.7 & $169 / 265$ & 63.8 & \\
\hline \multicolumn{6}{|c|}{ Main cause of preterm birth $\ddagger$} \\
\hline Hypertension & $157 / 194$ & 80.9 & $29 / 41$ & 70.7 & \multirow[t]{5}{*}{0.29} \\
\hline Bleeding & $81 / 117$ & 69.2 & $72 / 113$ & 63.7 & \\
\hline PPROM & $74 / 91$ & 81.3 & $53 / 81$ & 65.4 & \\
\hline Spontaneous prelabour & $43 / 81$ & 53.1 & $41 / 71$ & 57.7 & \\
\hline Other & $29 / 35$ & 82.9 & $26 / 34$ & 76.5 & \\
\hline \multicolumn{6}{|l|}{ Caesarean section } \\
\hline Yes & $271 / 352$ & 77.0 & $132 / 196$ & 67.3 & \multirow[t]{2}{*}{0.8} \\
\hline No & $112 / 165$ & 67.9 & $89 / 144$ & 61.8 & \\
\hline \multicolumn{6}{|l|}{ Sex } \\
\hline Boys & $210 / 281$ & 74.7 & $116 / 177$ & 65.5 & \multirow[t]{2}{*}{0.93} \\
\hline Girls & $173 / 236$ & 73.3 & $105 / 163$ & 64.4 & \\
\hline \multicolumn{6}{|c|}{$\begin{array}{l}\text { *Comparison of the distribution of antenatal steroids by risk factors of RDS in non-smokers and smokers. } \\
\text { tIntrauterine growth retardation defined as a birth weight ratio }<0.744^{31} \\
\text { ¥Comparison between five exclusive groups of causes defined in the following order: hypertension, either pre- } \\
\text { existing or due to pregnancy; maternal bleeding (abruptio placenta, placenta previa, and other uterine bleeding) } \\
\text { without hypertension; preterm premature rupture of membranes (PPROM) without hypertension or bleeding; } \\
\text { preterm spontaneous labour without hypertension, bleeding, or PPROM; all other causes, excluding hypertension, } \\
\text { bleeding, PPROM of preterm spontaneous bleeding. }\end{array}$} \\
\hline
\end{tabular}


without hypertension; preterm neonates born by caesarean section or vaginal delivery; preterm neonates with or without intrauterine growth restriction (results not shown).

Hospital mortality was similar in smokers and nonsmokers; mortality was lower in neonates whose mother had received steroids $(5.0 \% v 9.1 \%$, OR $=0.52,95 \%$ CI 0.29 to 0.95$)$. However, this beneficial effect of steroids on neonatal mortality was significant only in infants of nonsmokers $(4.2 \% v 11.9 \%$, OR $=0.32,95 \%$ CI 0.15 to 0.70$)$ and not smokers $(6.3 \% \vee 5.9 \%$, OR $=1.08,95 \%$ CI 0.39 to 3.1$)$. This differential effect of antenatal steroids on neonatal mortality by maternal smoking was significant $(\mathrm{p}=0.04)$, and this difference remained significant after adjustment for gestational age.

\section{DISCUSSION}

We found that maternal smoking was associated with a lower risk of RDS independently of known risk factors of RDS such as gestational age, birth weight, causes of preterm birth mainly maternal hypertension ${ }^{32}$ or bleeding, ${ }^{22}{ }^{23} \mathrm{sex}$, and mode of delivery. ${ }^{1433}$ Moreover, the protective effect of antenatal steroids on RDS was more effective in non-smokers in late pregnancy than in smokers; similar results were observed for hospital mortality.

The strengths of this study are that it was geographically defined and provided comprehensive preterm birth registration, restricting selection bias, and it included a large sample of patients. To the best of our knowledge, it is one of the few to have studied the effect of smoking on RDS in very preterm neonates,$^{14}$ and the first to have tested a differential effect of antenatal steroid treatment on fetal lung maturation in smokers and non-smokers while taking into account potential confounders.

Nevertheless, possible limitations have to be discussed. We analysed only singleton live births at 27-32 weeks, which may explain the relatively low incidence of RDS (41\%). The high rates of both antenatal steroids $(71 \%)$ and maternal smoking $(40 \%)$ in our cohort may also explain this low rate of RDS. $^{27}$

Information on smoking was collected by interview after birth, which may have led to under-reporting. However, differential under-reporting in combination with RDS status is very unlikely, as many babies without RDS had other serious complications. Besides, there is some evidence that misclassification on smoking status in pregnancy is limited and is unlikely to have a large influence on risk estimates. ${ }^{34-36}$

In our study, the mothers who did not smoke were more likely to have received antenatal steroid treatment. However, we checked that the indications assessed through gestational age, birthweight ratio, and main causes of preterm birth did not differ between smokers and non-smokers. Moreover, we checked that the differential relation of antenatal steroids to RDS in smokers and non-smokers did exist whether or not hypertension, intrauterine growth retardation, or caesarean section occurred.

Our study confirms the protective effect of smoking against RDS observed previously in moderate $e^{9-11}{ }^{13}$ and very ${ }^{14}$ preterm neonates. There is some biological evidence to support such an effect. Fetuses exposed to smoke reach sufficient lung maturity to minimise the risk of RDS about one week earlier than unexposed fetuses. ${ }^{37}$ Wuenschell et $a l^{38}$ have shown in vitro that nicotine induces stimulation of surfactant gene expression.

The crude odds ratio of RDS in relation to antenatal steroids that we observed is equivalent to the effect of one week of gestation and is similar to that described in Crowley's meta-analysis. ${ }^{15}$ Steroids enhance the synthesis of different proteins of surfactant in type II pneumocytes, stimulate activity of key enzymes of phospholipid synthesis, and accelerate the clearance of fetal lung. ${ }^{39}$ Our study suggests that the benefit of antenatal steroids may be reduced when fetal lungs have already been matured by cigarette smoking. To the best of our knowledge, none of the randomised trials on antenatal steroid treatment included in the meta-analysis of Crowley ${ }^{15}$ analysed the effectiveness of antenatal steroids on RDS after stratification on smoking status. Both antenatal steroids and smoking accelerate the maturation of fetal lung, but it is not known whether steroids and cigarette smoking act on the same metabolic pathways of the fetal lung maturation: if they do, this could explain why steroids appear to be less efficient in smokers. However, as well as RDS, antenatal steroids have been shown to reduce the risk of several other complications of prematurity, such as intraventricular haemorrhage and necrotising enterocolitis. ${ }^{15}$ Whether smoking in pregnancy would also modify these effects is not known.

Our study suggests that geographic or sociodemographic variations in the incidence of maternal smoking behaviour could partially explain the differences in incidence of RDS among studies. In trials, the random allocation of antenatal steroid treatment should provide balanced smoking rates in treated and untreated groups. However, our study suggests that further observational studies on RDS should take maternal smoking into account to ensure that the effect of some preventive treatments on RDS are not partially due to some confounding effect of smoking.

Further studies will have to assess if the differential effect of smoking on the association between RDS and steroids also exists in extremely preterm babies (22-26 weeks gestation) in whom RDS is more common and antenatal steroid treatment given less often. ${ }^{40}$ However, it has to be kept in mind that the surprising short term beneficial effect of maternal smoking on neonatal lung function is counteracted by the long term effects of smoking on infant lung function. ${ }^{41-44}$ Besides, maternal smoking increases the risk of very preterm birth $^{3-6}$ and thus the number of neonates at risk of RDS; even though preterm neonates born to smokers are less likely to have RDS than those born to non-smokers, their risk of RDS remains high, and, on the whole, smoking contributes to the level of this disease in the population.

\section{CONCLUSION}

Compared with non-exposed neonates, very preterm neonates exposed to maternal cigarette smoking in pregnancy experience a lower incidence of RDS. Antenatal steroid treatment reduces the risk of RDS in very preterm neonates born to non-smokers as well as to those born to smokers, but the benefit is smaller in smokers than non-smokers. There is no evidence that pregnant smokers at risk of delivering very prematurely should not be offered antenatal steroid treatment.

\section{ACKNOWLEDGEMENTS}

The Epipage cohort is financially supported by Institut National de la Santé et de la Recherche Médicale, Merck-Sharp and Dohme-Chibret, Fondation de la Recherche Médicale, and Direction Générale de la Santé (Ministry of Health).

\section{Authors' affiliations}

A Burguet, A Menget, Department of Neonatology, University Hospital, Besançon, France

A Burguet, M Kaminski, G Breart, B Larroque, Epidemiological Research Unit on Perinatal and Women's Health, INSERM U149, Villejuif, France

P Truffert, Department of Neonatology, University Hospital, Lille, France L Marpeau, Department of Obstetrics and Gynaecology, University Hospital, Roven, France

M Voyer, Department of Neonatology, Institut de Puériculture, Paris, France 
J C Roze, Department of Neonatology, University Hospital, Nantes, France

B Escande, Department of Neonatology, University Hospital Strasbourg, France

G Cambonie, Department of Pediatrics, University Hospital Montpellier, France

J M Hascoet, Department of Neonatology, University Hospital, Nancy, France

H Grandjean, INSERM U558, Toulouse, France

Competing interests: none declared

\section{APPENDIX}

\section{COMPOSITION OF THE EPIPAGE GROUP}

INSERM U149: B Larroque (national coordinator), PY Ancel, B Blondel, G Bréart, M Dehan, M Garel, M Kaminski, F Maillard, C du Mazaubrun, P Missy, F Sehili, K Supernant. Alsace: M Durand, J Matis, J Messer, A Treisser (Hôpital de Hautepierre, Strasbourg)

Franche-Comte: A Burguet, L Abraham-Lerat, A Menget,

P Roth, JP Schaal, G Thiriez (CHU St-Jacques, Besançon).

Haute-Normandie: C Lévêque, S Marret, L Marpeau (Hôpital Charles Nicolle, Rouen)

Languedoc-Roussillon: P Boulot, JC Picaud (Hôpital Arnaud de Villeneuve, Montpellier), AM Donadio, B Ledésert (ORS Montpellier).

Lorraine: M André, JL Boutroy, J Fresson, P Vert (Maternité régionale, Nancy)

Midi-Pyrénées: C Arnaud, S Bourdet-Loubère, H Grandjean (INSERM U558, Toulouse), M Rolland (Hôpital des Enfants, Toulouse).

Nord-Pas de Calais: C Leignel, $\mathrm{P}$ Lequien, V Pierrat, F

Puech, D Subtil, P Truffert (Hôpital Jeanne de Flandre, Lille).

Pays de Loire: G Boog, V Rouger-Bureau, JC Rozé (Hôpital Mère-Enfant Nantes).

Paris Petite-Couronne: PY Ancel, G Bréart, M Kaminski, C du Mazaubrun (INSERM U 149 Paris), M Dehan, V Zupan (Hôpital Béclère, Clamart), M Vodovar, M Voyer (Institut de Puériculture, Paris).

\section{REFERENCES}

1 Simpson WJ, Linda L. A preliminary report on cigarette smoking and the incidence of prematurity. Am J Obstet Gynecol 1957;73:808-15.

2 Mitchell EA, Thompson JM, Robinson E, et al. Smoking, nicotine and tar and risk of small for gestational age babies. Acta Paediatr 2002;91:323-8.

3 Kyrklund-Blomberg NB, Cnattingius S. Preterm birth and maternal smoking risks related to gestational age and onset of delivery. Am J Obstet Gynecol 1998; 179:1051-5.

4 Ancel PY, Saurel-Cubizolles MJ, Di Renzo GC, et al. Very and moderate preterm births: are the risk factors different? $\mathrm{Br} J$ Obstet Gynaecol 1999; 106: 1162-70

5 Burguet A, Kaminski M, Abraham-Lerat L, et al. The complex relationship between smoking in pregnancy and very preterm delivery. Results of the Epipage study. Br J Obstet Gynaecol 2004;111:258-65.

6 Cnattingius S, Granath F, Petersson G, et al. The influence of gestational age and smoking habits on the risk of subsequent preterm deliveries. N Engl J Med 1999:341:943-8.

7 Andres RL, Day MC. Perinatal complications associated with maternal tobacco use. Semin Neonatol 2000;5:231-41.

8 Joad JP. Smoking and pediatric respiratory health. Clin Chest Med 2000;21:37-46, vii-viii.

9 Curet LB, Rao AV, Zachman RD, et al. Maternal smoking and respiratory distress syndrome. Am J Obstet Gynecol 1983;147:446-50.

10 White E, Shy KK, Daling JR, et al. Maternal smoking and infant respiratory distress syndrome. Obstet Gynecol 1986;67:365-70.

11 Naeye RL. Disorders of the placenta, fetus and newborn: diagnosis and clinical significance. St Louis, MO: CV Mosby Co, 1992:84

12 Hanlon-Lundberg KM, Williams M, Rhim T, et al. Accelerated fetal lung maturity profiles and maternal cocaine exposure. Obstet Gynecol 1996;87:128-32.

13 Strandjord TP, Emanuel I, Williams MA, et al. Respiratory distress syndrome and maternal birth weight effects. Obstet Gynecol 2000;95:174-9.

14 Kavvadia V, Greenough A, Dimitriou G, et al. Influence of ethnic origin on respiratory distress syndrome in very premature infants. Arch Dis Child Fetal Neonatal Ed 1998;78:F25-8.
15 Crowley P. Prophylactic corticosteroids for preterm birth. Cochrane Database Syst Rev 2000;(2):CD000065.

16 Collaborative group on antenatal steroid therapy. Effect of antenatal dexamethasone administration on the prevention of respiratory distress syndrome. Am J Obstet Gynecol 1981;141:276-87.

17 Silver RK, Vyskocil C, Solomon SL, et al. Randomized trial of antenatal dexamethasone in surfactant-treated infants delivered before 30 weeks' gestation. Obstet Gynecol 1996;87:683-91.

18 Ee L, Hagan R, Evans S, et al. Antenatal steroids, condition at birth and respiratory morbidity and mortality in very preterm infants. J Paediatr Child Health 1998;34:377-83.

19 Vermillion ST, Soper DE, Bland ML, et al. Effectiveness of antenatal corticosteroid administration after preterm premature rupture of the membranes. Am J Obstet Gynecol 2000;183:925-9.

20 Hacking D, Watkins A, Fraser S, et al. Respiratory distress syndrome and antenatal corticosteroid treatment in premature twins. Arch Dis Child Fetal Neonatal Ed 2001;85:F77-8.

21 Elimian A, Verma U, Canterino J, et al. Effectiveness of antenatal steroids in obstetric subgroups. Obstet Gynecol 1999;93:174-9.

22 Lin C, Wang S, Hsu $Y$, et al. Risk for respiratory distress syndrome in preterm infants born to mothers complicated by placenta previa. Early Hum Dev $2001 ; 60: 215-24$

23 Baud O, Zupan V, Lacaze-Masmonteil T, et al. The relationships between antenatal management, the cause of delivery and neonatal outcome in a large cohort of very preterm singleton infants. Br J Obstet Gynaecol 2000;107:877-84

24 Berkowitz GS, Papiernik E. Epidemiology of preterm birth. Epidemiol Rev 1993; 15:414-43.

25 Lumley J. The epidemiology of preterm birth. Baillieres Clin Obstet Gynaecol 1993;7:477-98.

26 Kramer MS, Demissie K, Yang H, et al. The contribution of mild and moderate preterm birth to infant mortality. JAMA 2000;284:843-9.

27 Robertson PA, Sniderman SH, Laros RK Jr, et al. Neonatal morbidity according to gestational age and birth weight from five tertiary care centers in the United States, 1983 through 1986. Am J Obstet Gynecol 1992;166:1629-41

28 Lumley J, Oliver S, Waters E. Interventions for promoting smoking cessation during pregnancy. Cochrane Database Syst Rev 2000;(2):CD001055.

29 Larroque B, Samain H, Groupe Epipage. Etude Epipage: mortalité des enfants grands prématurés et état $d$ 'avancement du suivi. [Epipage study: outcome to discharge from hospital for very preterm infants and update on the follow-up.] J Gynecol Obstet Biol Reprod 2001;30:S33-41.

30 Larroque B, Bréart $G$, Kaminski $M$, et al. Survival of very preterm infants: Epipage, a population-based cohort study. Arch Dis Child Fetal Neonatal Ed 2004;89:F139-44.

31 Hadlock FP, Harrist RB, Martinez-Poyer J. In utero analysis of fetal growth: a sonographic weight standard. Radiology 1991;181:129-33.

32 Tubman TR, Rollins MD, Patterson C, et al. Increased incidence of respiratory distress syndrome in babies of hypertensive mothers. Arch Dis Child 1991:66(1 Spec No):52-4.

33 Dani C, Reali MF, Bertini G, et al. Risk factors for the development of respiratory distress syndrome and transient tachypnoea in newborn infants. Italian Group of Neonatal Pneumology. Eur Respir J 1999;14:155-9.

34 Verkerk PH, Buitendijk SE, Verloove-Vanhorick SP. Differential misclassification of alcohol and cigarette consumption by pregnancy outcome. Int J Epidemiol 1994;23:1218-25.

35 Burguet A, Berard M, Woronoff AS, et al. Appréciation du tabagisme maternel et néonatal par un dosage de la cotinine urinaire par chromatographie liquide haute performance. [An appreciation of maternal and neonatal smoking with high-performance liquid chromatographic determination of urinary cotinine.] J Gynecol Obstetr Biol Reprod 2001;30:166-73.

36 Klebanoff MA, Levine RJ, Morris CD, et al. Accuracy of self-reported cigarette smoking among pregnant women in the 1990s. Paediatr Perinat Epidemiol $2001 ; 15: 140-3$.

37 Lieberman E, Torday J, Barbieri R, et al. Association of intrauterine cigarette smoke exposure with indices of fetal lung maturation. Obstet Gynecol 1992;79:564-70.

38 Wuenschell CW, Zhao J, Tefft JD, et al. Nicotine stimulates branching and expression of SP-A and SP-C mRNAs in embryonic mouse lung culture. Am J Physiol 1998;274:L165-70.

39 Ballard PL, Ballard RA. Scientific basis and therapeutic regimens for use of antenatal glucocorticoids. Am J Obstet Gynecol 1995;173:254-62.

40 Bronstein JM, Goldenberg RL. Practice variation in the use of corticosteroids: a comparison of eight data sets. Am J Obstet Gynecol 1995;173:296-8.

41 Stick SM, Burton PR, Gurrin L, et al. Effects of maternal smoking during pregnancy and a family history of asthma on respiratory function in newborn infants. Lancet 1996;348:1060-4.

42 Hoo AF, Henschen M, Dezateux C, et al. Respiratory function among preterm infants whose mothers smoked during pregnancy. Am J Respir Crit Care Med 1998; 158:700-5.

43 Milner AD, Marsh MJ, Ingram DM, et al. Effects of smoking in pregnancy on neonatal lung function. Arch Dis Child Fetal Neonatal Ed 1999;80:F8-14.

44 Sekhon HS, Keller JA, Benowitz NL, et al. Prenatal nicotine exposure alters pulmonary function in newborn rhesus monkeys. Am J Respir Crit Care Med 2001;164:989-94. 